International Section

Arch. Esp. Urol., 61, 3 (459-463), 2008

\title{
BIOMAGNETIC ACTIVITY IN PROSTATE CANCER AND BPH
}

\author{
P. Anninos, I. Papadopoulos' and A. Kotini.
}

Lab of Medical Physics and Department of Urology'. Medical School. Democritus University of Thrace.

Alex/polis. Greece.

\begin{abstract}
Summary.- OBJECTIVE: The aim of this study was to investigate the role of biomagnetic activity measurements in detecting prostate malignancies, in differentiating cancerous from benign prostate lesions and in generally improving our understanding of prostate cancer biology.

METHODS: Magnetic recordings were obtained from 47 patients with palpable prostate lesions. Twenty-four had prostate carcinoma and 23 benign prostatic hyperplasia $(B P H)$.

RESULTS: The magnetic field recorded in the $2-7 \mathrm{~Hz}$ frequency range was of high amplitude in most (95\%) malignant lesions $248 \pm 82 \mathrm{Ft} / \sqrt{ } \mathrm{Hz}$ ) and of low amplitude
\end{abstract}

in most (95\%) benign ones (166 $31 \mathrm{Ft} / \mathrm{VHz})$. These findings displayed significant difference $(p=0.0021)$.

CONCLUSIONS: Prostate cancer emits higher biomagnetic activity than $\mathrm{BPH}$. This finding confirms the higher angiogenic activity of prostate cancer. The use of this method is safe and seems promising.

Keywords: Prostate cancer. Biomagnetic activity. SQUID

Resumen.- OBJETIVO: Investigar el papel de las mediciones de la actividad biomagnética en la detección de los tumores malignos prostáticos, en la diferenciación entre lesiones cancerígenas y benignas, y en mejorar de forma general nuestro conocimiento de la biología del cáncer de próstata.

MÉTODOS: Se obtuvieron registros magnéticos en 47 pacientes con lesiones prostáticas palpables. Veinticuatro tenían cáncer de próstata y 23 hiperplasia benigna de próstata.

RESULTADOS: Los campos magnéticos registrados en el rango de frecuencias entre 2-7 fueron de gran amplitud $(248 \pm 82 \mathrm{Ft} / \mathrm{VHz}$ ) en la mayoría de las lesiones malignas $(95 \%$ ) y de baja amplitud $(166 \pm 31 \mathrm{Ft} / \mathrm{VHz}$ ) en la mayoría de las benignas (95\%). Estos hallazgos tuvieron diferencias significativas ( $p=0.0021)$.

CONCLUSIONES: Cáncer de próstata emite mayor actividad biomagnética que la HBP. Este hallazgo confirma la mayor actividad angiogénica del cáncer de próstata. La utilización de este método es segura y parece prometedora.

Palabras clave: Cáncer de próstata. Actividad biomagnética. SQUID. 


\section{INTRODUCTION}

Prostate cancer is the second most common malignancy in the male population over the age of 50 and the third most lethal neoplasm following lung and colon cancer. The incidence of prostate cancer has risen significantly during the recent past and, given its important social implications, has resulted in a great medical and socioeconomic challenge, which is to achieve its diagnosis at the earlier possible stage. Obtaining prostate tumour samples surgically is problematic because the malignancy is heterogeneous and multifocal and early stage tumours are nonpalpable. The use of newly introduced diagnostic techniques, such as transrectal ultrasound (TRUS) assisted by computerized methods of interpreting transrectal ultrasound information by artificial neural network analysis (ANNA) has helped substantially in prostate cancer identification, but has not provided a finite solution to the problem.

Recent widespread interest in telomerase was identified by the discovery that unlimited proliferation in most cancer and immortal cells is highly dependent on the activity of this ribonucleoprotein enzyme complex, and this marker is a promising candidate for the differential detection of benign and malignant prostate lesions $(1,2)$. An interesting advance that has taken place recently was the introduction of the biomagnetometer into clinical practice. This technique has been used successfully in detecting breast tumours, in differentiating ovarian lesions, and in studying the activity of the brain and the hemodynamics of the umbilical cord (3-6). In view of the fact that prostate cancer remains an insidious and intractable disease, which is often diagnosed at a late stage and is accompanied by high mortality, new technologies need to be used to detect this cancer at an early stage and to improve our understanding of its bio-oncological behaviour.

In this article, we report on the potential diagnostic value of biomagnetic activity measurements in assessing prostate lesions. Such measurements of the biomagnetic activity of different prostate lesions (prostate cancer, benign prostatic hyperplasia) are still not known, to the best of our knowledge.

\section{METHODS}

Magnetic recordings were obtained from 47 patients with prostate lesions. Of these patients, 27 bore carcinomas and 23 had benign prostatic hyperplasia (BPH). The exact nature of these lesions was determined histologically. The age of the patients ranged from 48 to 72 years. Serum PSA was measured before biopsy. The Tandem-R PSA assay (Hybritech), which was used for all PSA measurements, has a reference range of 0 to $4 \mathrm{ng} / \mathrm{mL}$. In prostate cancer cases, the Gleason System (7) was used for histological grading and the TNM classification system (8) for staging.

We used a single channel second order gradiometer (DC SQUID mode1601, Biomagnetic Technologies) in an electrically shielded room with the patient lying supine on a wooden bed, free of any metallic objects. Measurements of the biomagnetic prostate activity were conducted by use of a detector placed on the abdomen above the symphysis pubis.

In all patients eight points were selected for examination. Four points were located at the very centre of the prostate lesion, whereas the other four points at the periphery of the examined area. For each point, 32 recordings of 1 -second duration each were taken with the biomagnetometer detector placed $3 \mathrm{~mm}$ above the recording position. This allows the maximal magnetic flux to pass through the coil with little deviation from the vertical direction.

The sampling frequency was $256 \mathrm{~Hz}$ with a bandwidth between 1 and $100 \mathrm{~Hz}$. Using an AD converter, the analogue signals were converted to digital ones and, after Fourier statistical analysis, the average spectral densities from the 32 records of the magnetic field strength were obtained from each one of the eight points measured in the frequency range 2-7 $\mathrm{Hz}$. By convention, the maximal value was used when assessing the prostate lesions. All biomagnetic assays were performed before histological examination of prostate lesions and the operators were blinded to clinical (digital examination, PSA) and transrectal ultrasound (TRUS) findings.

\section{RESULTS}

The waveforms of the prostatic lesions (raw data) were of high amplitude in most prostatic carcinomas and of low amplitude in most BPH patients. There were, however, three cases in the cancer group $(12,5 \%)$ and another three in the BPH group $(13 \%)$, which showed biomagnetic recordings of low and high amplitudes respectively. In all cases, the frequencies considered were distributed within the range of 2-7 Hz. The corresponding spectral densities of the magnetic field were shown after statistical Fourier analysis. They were of high spectral amplitude in the malignant prostatic neoplasms and of low spectral amplitude in benign prostatic lesions. The maximum total average of spectral amplitudes emitted by prostatic carcinomas was $248.82 \mathrm{Ft} / \mathrm{VHz}$ (range 90-484 $\mathrm{Ft} / \sqrt{ } \mathrm{Hz}$ ) in the 2-7 $\mathrm{Hz}$ frequency band. However, 
the maximum total average spectral ampl itude emitted by $\mathrm{BPH}$ was $165,45 \mathrm{Ft} / \mathrm{VHz}$ (range $88-402 \mathrm{Ft}$ / $\sqrt{ } \mathrm{Hz})$ in the 2-7 Hz frequency band. The difference between prostatic carcinomas and BPH was of high statistical significance (t-test $p=0.0021)$.

Analysis of the prostate carcinomas revealed a TNMclassification of stages T 1-2 for 9 of 24 carcinomas and stages T 3-4 in 15 cases. With regard to malignancy, 14 tumours were classed as low grade, 7 as intermediate and 3 as high grade. Regarding the concentration of PSA, the patients were divided in three groups (less than $10 \mathrm{ng} / \mathrm{mL}$ ), 10 to $30 \mathrm{ng} / \mathrm{mL}$ and $30 \mathrm{ng} / \mathrm{mL}$ or more.

Table I shows the relationship between $T$ stage, grade and serum PSA before measurement of biomagnetic activity in prostatic carcinomas. The T $1-2$ tumours showed an average biomagnetic activity of $237 \pm 80 \mathrm{Ft} / \sqrt{ } \mathrm{Hz}$ and the $\mathrm{T} 3-4$ tumours $245 \pm 93 \mathrm{Ft} / \sqrt{ } \mathrm{Hz}$. The difference between consecutive groups was not statistically significant $(p=0,83)$. There was not a significant statistical correlation between Gleason's combined score and the responding biomagnetic activities $(p=0,86)$. A comparison of average concentration of PSA in the three groups in relation to biomagnetic activity revealed no statistically significant difference between the groups $P S A<10$ vs. $10<P S A<30(p=0,41)$ but statistically significant difference between the groups $10<P S A<30$ vs. PSA $>30$ nglml $(p=0,0052)$.

\section{DISCUSSION}

Angiogenesis is a term describing new blood vessel formation and is considered to play an important role in oncogenesis, in general, and also in tumour spread and metastatic growth. The angiogenic activity seems to be the result of a balance between angiogenic stimulators and inhibitors that may be produced by fumour cells, as well as benign host cells (macrophages, mast cells and stromal components).

Tumour hyperemia is known as being related to new blood vessel formation within the tumour and to vasodilatation of existent blood vessels. Viable tumour cells release diffusible angiogenic factors, which stimulate new capillary growth and endothelial mitosis in vivo, even when tumour proliferation has

TABLE I. COMPARISON OF TUMOUR CHARACTERISTICS ISTAGE T, GLEASON SCORE, SERUM PSAI WITH BIOMAGNETIC ACTIVITY IN 24 PROSTATIC CARCINOMAS.

\begin{tabular}{|c|c|c|}
\hline & $\begin{array}{l}\text { Biomagnetic Activity } \\
\text { Mean } \pm \mathrm{SD}(\mathrm{Ft} / \sqrt{ } \mathrm{Hz})\end{array}$ & Significance \\
\hline Stage & & \\
\hline TI-2 (n=9) & $237 \pm 80$ & \\
\hline T3-4 $(n=15)$ & $245 \pm 93$ & $p=0,83$ \\
\hline Gleason score & & \\
\hline Low grade $(n=14)$ & $245 \pm 102$ & \\
\hline Intermediate $(n=7)$ & $237 \pm 49$ & \\
\hline High grade $(n=3)$ & $241 \pm 111$ & $p=0,86$ \\
\hline PSA (nglmL) & & \\
\hline$A<10$ & $249 \pm 93$ & $A$ vs $B(p=0,41)$ \\
\hline B $10-30$ & $290 \pm 49$ & A vs $C(p=0,097)$ \\
\hline$C>31$ & $165 \pm 30$ & $B$ vs $C(p=0,0052)$ \\
\hline
\end{tabular}


been arrested by irradiation. Folkman proposed a hypothesis that "once tumour take occurs, every further increase in new capillaries which converge upon the tumour, results in early growth" (9-11).

According to this concept, a small focus of tumour cells (containing less than 10 cells in a volume of a few cubic millimetres) could not increase infinitely without the induction of angiogenesis. Furthermore, this focus of a few millimetres in diameter depends on the induction of functional microcirculation from the surrounding host tissue. It is obvious that malignant tumours induce the growth of an independent and characteristic vascular network on their own. The tumour vasculature is highly heterogeneous and does not conform to the standard normal vascular organization (i.e. artery to arteriole and capillaries to post capillary venule to venule to vein). A key difference between normal and tumour vessels is that the later are dilated, saccular and tortuous and may contain tumour cells within the endothelial lining of the vessel wall.

Although a quantitative relationship between angiogenesis, metastasis and prognosis has been noted for prostate cancer, the contribution of angiogenesis to certain attributes of this cancer, like slow proliferation and low progression rate, have not been thoroughly investigated up to date (12-14).

The biomagnetic activity of malignant tissues is a reflection of tumour hyperemia and neo-vascularization, as well as of existent vessels vasodilatation. This biomagnetic activity is caused by the movement of ions across the plasma membrane. Lately, the measurement of biomagnetic activity by use of the SQUID biomagnetometer has been introduced into clinical practice. Real-time, 3D localization of the prostate for intensity-modulated radiotherapy can be accomplished with passively charged radio frequency transmitters and superconducting quantum interference device (SQUID) magnetometers.

McGary JE has presented the theoretical foundation for designing a real-time, 3D prostate localization system including the associated physical parameters and has demonstrated the feasibility and physical limitations for such a system (15). Anastasiadis et al. measured the biomagnetic activity of ovarian (4) and breast (3) lesions and found that it was higher, compared to benign lesions, in $95 \%$ of malignant neoplasms of these organs. Furthermore, the authors discovered significant differences in the amplitude of biomagnetic activity between breast and ovarian carcinomas.
Regarding prostate lesions, the data presented in this study justify a novel approach to the magneto-prostato-gram (MPG) and suggest that this method of measuring the biomagnetic activity can be potentially exploited in differentiating malignant and benign prostate diseases. This is not unexpected as malignant tissues, by virtue of their expansion, vascularity, and thus increased ionic movements, produce magnetic fields of higher intensity than benign hyperplasic tissues growing more slowly. In the prostatic carcinomas we studied, the biomagnetic activity was found low (mean $248 \pm 82 \mathrm{Ft} / \sqrt{ } \mathrm{Hz}$ ) compared to carcinomas of the breast (mean $754 \pm 305 \mathrm{Ft} / \sqrt{ } \mathrm{Hz}$ ). This finding can be explained by the lower angiogenic activity of prostate carcinomas, in contrast to other malignancies, and could help in resolving certain features of this carcinoma, namely slow proliferation and low progression rate.

It is known that prostate cancer stage $(T)$ is closely related to tumour volume. In the present study, tumour stage (T) did not show a statistically significant correlation to biomagnetic activity. This fact could be explained by taking into consideration the increased angiogenic activity also in early tumour stages.

Comparison of biomagnetic activity with respect to Gleason-score (grade) and to PSA serum levels did not show statistically significant differences. Therefore, it seems as though biomagnetic measurements of prostate lesions may prove a useful method in detecting prostatic carcinomas and may offer additional information in better understanding the biology of prostate cancer. The method is non-invasive, reliable, rapid and easy to interpret. Furthermore, it is totally harmless and well tolerated by the patients. The differences reported in this study between carcinomas and $\mathrm{BPH}$ are apparently due to malignancy itself and are not influenced to any extent by other factors, such as tumour size. A disadvantage of the technique used for our measurements is obviously the relatively big distance between the suprapubic biomagnetic detector and the centre of the prostate gland $(3-5 \mathrm{~cm})$.

\section{CONCLUSIONS}

We are currently targeting our efforts in creating a transrectal SQUID detector that would be almost adjacent to the prostate, thus able to provide a more accurate recording of the biomagnetic profile of the gland. Nonetheless, the precise role of biomagnetic activity in prostate cancer detection and biology remains to be further elucidated by extensive and thorough investigation in studies to come. 
REFERENCES AND RECOMENDED READINGS (*of special interest, ${ }^{* *}$ of outstanding interest)

*1. BOTCHKINA, G.I.; KIM, R.H.; BOTCHKINA, I.L. et al: "Noninvasive detection of prostate cancer by quantitative analysis of telomerase activity". Clin Cancer Res. May 1;11:3243, 2005.

**2. LOCH, T.; LEUSCHNER, I.; GENBERG, C. et al: "Artificial neural network analysis (ANNA) of prostatic transrectal ultrasound”. Prostate; $15: 198$, 1999.

**3. ANASTASIADIS, P.; ANNINOS, P.; SIVRIDIS, E.: "Biomagnetic activity in breast lesions". The Breast 3 :177, 1994.

**4. ANASTASIADIS, P.; ANNINOS, P.; KOTINI, A. et al: "Biomagnetic activity in ovarian lesions". Anticancer Res; 18: 3753, 1998.

**5. ANASTASIADIS, P.; ANNINOS, P.; DIAMANTOPOULOS, P. et al: "Fetal magnetoencephalographic mapping in normal and pre-eclamptic pregnancies". J Obstet Gynaecol; 17 :123, 1997.

**6. ANASTASIADIS, P.; ANNINOS, P.; ADAMOPOULOS, A. et al: "The hemodynamics of the umbilical artery in normal and pre-eclamptic pregnancies. A new application of SQUID biomagnetometry". J. Perinat Med; 25: 35, 1997.

7. GLEASON, O.F.: "Classification of prostate car- cinomas (part I). Cancer Chemother Rep; 5:125, 1966.

8. HERMANEK. P.; AND SOKIN, L.H.: "TNM classification, 4th ed, 2nd rev. Berlin: Spinger; 141, 1992.

*9. FOLKMAN, J.: "Tumor angiogenesis correlates with metastasis in invasive prostate carcinoma. Am. J. Pathol. 143:401, 1999.

*10. FOLKMAN, J.; MALREL, E.; ABEMETHY, C. et al: Isolation of a tumour factor responsible for angiogenesis. J Exp Med; 133; 275, 1971.

*11. FOLKMAN, J.: "Tumour angiogenesis. Adv Cancer Res; 43 :175, 1985.

*12. BOAE, M.; OFFERSEN, B.V.; NESTROSLASH, M. et al: "Microvessel density predicts survival in prostate cancer patients subjected to watchful waiting. Br J Cancer; 78: 7940, 1998.

13. KLAGSBRUN, M. AND D' AMORE, P.A.: "Regulators of angiogenesis. Ann Rev Physiol; 53-217, 1991.

*14. AUERBACH, R.: "Angiogenesis-including factors: a review. In: Pick E, editor. Lymphokines. London, Academic Press: 69, 1981.

**15. McGARY, J.E.: "Theoretical foundation for realtime prostate localization using an inductively coupled transmitter and a superconducting quantum interference device (SQUID) magnetometer system. J. Appl. Clin. Med. Phys. 5:29, 2004. 